\title{
Morphological, toxicological and molecular characterization of a benthic Nodularia isolated from Atlantic estuarine environments
}

\author{
Viviana R. Lopes ${ }^{\text {a,b }}$, Agostinho Antunes ${ }^{\text {a }}$, Martin Welker ${ }^{c}$, Rosário F. Martins ${ }^{\text {a,d }}$, \\ Vítor M. Vasconcelos ${ }^{\mathrm{a}, \mathrm{b}, *}$

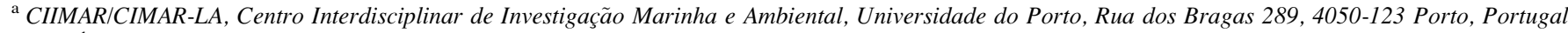 \\ ${ }^{\mathrm{b}}$ Departamento de Zoologia e Antropologia, Faculdade de Ciências, Universidade do Porto, Rua do campo Alegre, 4169-007 Porto, Portugal \\ ${ }^{\mathrm{c}}$ Technische Universitat Berlin, Institute of Chemistry, Department of Biochemistry and Molecular Biology, Franklinstrasse 29, 10587 Berlin, Germany \\ ${ }^{\mathrm{d}}$ Escola Superior de Tecnologia da Saúde do Porto, Instituto Politécnico do Porto, R. Valente Perfeito 322, 4400-330 Vila Nova de Gaia, Portugal
}

Received 4 May 2009; accepted 3 November 2009

Available online 26 November 2009

\begin{abstract}
A polyphasic study of a benthic Nodularia isolate (LEGE06071) from an Atlantic environment, specifically salt pans, was performed. LEGE06071 resembled both type strains of Nodularia sphaerocarpa and Nodularia harveyana, while ACOI00729 (purchased isolate) was identified as $N$. sphaerocarpa. The length and width of vegetative cells varied from 3.10 to $3.15 \mu \mathrm{m}$ and from 3.71 to $4.25 \mu \mathrm{m}$, respectively, while heterocyts were $3.91-4.89 \mu \mathrm{m}$ long and $4.20-4.74 \mu \mathrm{m}$ wide. None of the isolates had aerotopes. The sequencing of the 16S rRNA gene from the two Nodularia isolates indicated that they belonged neither to Nodularia spumigena nor N. harveyana. Nodularin and other cyanotoxin synthesis-associated genes could not be detected, nor could nodularin production be detected by ELISA. However, MALDI-TOF analysis of LEGE06071 revealed the presence of other compounds, namely, glycolipids. Hence, toxicological screenings against Artemia nauplii, Escherichia coli and Salmonella typhimurium were performed. Toxic effects could only be observed against Artemia, with $48 \mathrm{~h}-\mathrm{LC}_{50}$ values for the aqueous and crude extract of methanol of $53.21 \mathrm{mg} \mathrm{ml}^{-1}$ and $17.81 \mathrm{mg} \mathrm{ml}^{-1}$, respectively. This study presents the first evidence of a non-nodularin-producing Nodularia isolate in Atlantic salt pan ecosystems and its potential ecotoxicity against Artemia sp.
\end{abstract}

(C) 2009 Elsevier Masson SAS. All rights reserved.

Keywords: Atlantic ecosystems; Ecotoxicity; Estuary; Nodularia sp.; 16S ribosomal RNA

\section{Introduction}

The diversity, ecology and toxic properties of benthic Nodularia species, and in particular those from Atlantic environments, namely Portuguese estuaries, have been poorly studied. The few existing studies on benthic Nodularia have been mainly restricted to the Baltic Sea [14]. Nodularia distribution is reported in marine and brackish waters from

\footnotetext{
* Corresponding author at: CIIMAR/CIMAR-LA, Centro Interdisciplinar de Investigação Marinha e Ambiental, Universidade do Porto Rua dos Bragas 289, 4050-123 Porto, Portugal. Tel.: +351 223401814; fax: +351 223390608.

E-mail addresses: vlopes@ciimar.up.pt (V.R. Lopes), aantunes@ncifcrf. gov (A. Antunes), martin.welker@tu-berlin.de (M. Welker), mrm@estsp.ipp. pt (R.F. Martins), vmvascon@fc.up.pt (V.M. Vasconcelos).
}

a few European countries as well as the United States, Australia and New Zealand [4,32].

Nodularia habitats range from slightly brackish coastal and saline waters to inland alkaline lakes, but are only rarely found in freshwater reservoirs and in soil $[6,14,19]$. The genus Nodularia comprises diazotrophic filamentous cyanobacteria, which can occur as planktonic, benthic and terrestrial species. It is composed of four defined planktonic species, Nodularia spumigena, Nodularia littorea, Nodularia crassa and Nodularia baltica, and three benthic ones, Nodularia harveyana, Nodularia sphaerocarpa and Nodularia willei. Differences in size and shape of the planktonic species diverge from those of benthic species as well as their ability to form aerotopes and to produce nodularin [15]. 
Planktonic Nodularia species occur mainly in marine and brackish biotopes, saline coastal and inland waters, and swamps ranging from temperate to subtropical areas. An uncommon benthic case is $N$. willei, which occurs in mats covering plants or muddy bottoms, mostly rice fields and brackish swamps throughout the tropics. The benthic $N$. sphaerocarpa is a freshwater alkaliphilic species existing mainly in temperate zones (Europe), littorals of lakes and on limestone substrates. $N$. harveyana is found in saline environments and has a cosmopolitan occurrence [14,19].

The taxonomy of Nodularia species based on morphological characters has never been simple. Occasionally, diacritical markers, for example, the presence of gas vesicles, may change during culture conditions, rendering species classification extremely complex [14]. Studies using phylogenetic markers such as small subunit ribosomal RNA (16S rRNA), internal transcribed spacers (ITSs) and phycocyanin genes, among others, are common and helpful tools for assessing the diversity and evolutionary relationships of cyanobacteria. The most popular marker for phylogenetic relationships among cyanobacteria is $16 \mathrm{~S}$ rRNA, though it may be less informative for intrageneric level analysis [3]. According to Wilmotte [39], analysis of the 16S rRNA gene is not usually congruent with morphological features. Despite its limitations, Lehtimaki et al. and Lyra et al. $[18,19]$ showed that studies involving $16 \mathrm{~S}$ rRNA gene sequences are helpful for differentiating toxic from non-toxic strains of Nodularia and for pointing out its close relatedness.

Nodularia cyanobacteria are known to form blooms which can be toxic and cause chronic effects at several levels of the food chain $[5,11]$. The genus Nodularia is well-known due to the toxicity of $N$. spumigena, which produces nodularin, a hepatotoxin [19]. Nodularin was first reported in Australia, where it caused animal poisoning [7]. Nodularin is a cyclic heptapeptide with a cyclo-(D-MeAsp-L-arginine-Adda-Dglutamate-2-(methylamino)-2-dehydrobutyric-acid) structure [33]. It is non-ribosomally synthesized by a large multienzyme complex containing non-ribosomal peptide synthetase (NRPS) and polyketide synthetase (PKS) domains, as well as putative transposases and tailoring enzyme coding genes $[10,24,25]$. The toxicity of nodularin hepatotoxin is linked to inhibition of protein phosphatases 1 and 2A. Other toxic effects not linked to nodularin have been described in Nodularia against a free-living nematode, Cephaloboides oxycerca [27]. Moreover, the allelopathic activity of lipophilic secondary metabolites of a $N$. harveyana extract, as well as the antibacterial, antifungal and antibiotic activity of other Nodularia extracts, have been demonstrated [28].

To our knowledge, no previously published study reported the presence of Nodularia strains in European Atlantic estuarine environments. In this study, we characterized, at the morphological, toxicological and molecular level, a Nodularia isolate from a mainland estuary in Portugal. We also compared the morphometric characteristics of our isolate with a purchased isolate originally collected on the Madeira Island. The 16S rRNA phylogenetic relationships of those two Atlantic Nodularia isolates were compared with others collected worldwide. Furthermore, we analyzed the presence or absence of the nodularin synthetase gene as well other genes involved in production of common cyanotoxins. Finally, we assessed the ecotoxic, genotoxic and mutagenic activity of these Atlantic Nodularia to evaluate their potential environmental risk.

\section{Materials and methods}

\subsection{Cyanobacterial isolation and culture}

The strains of Nodularia used in this study were isolated from a water sample collected in the River Vouga estuary located in central Portugal $\left(40^{\circ} 38^{\prime} 32.87^{\prime \prime} \mathrm{N}, 8^{\circ} 39^{\prime} 47.85^{\prime \prime} \mathrm{O}\right.$; LEGE06071); the Madeira Island strain $\left(32^{\circ} 45^{\prime} 38.55^{\prime \prime} \mathrm{N}\right.$; $16^{\circ} 57^{\prime} 34.10^{\prime \prime} \mathrm{W}$; ACOI0729) was purchased at the Collection of Algae of Coimbra. LEGE06071 was isolated by a micromanipulation technique and grown in $\mathrm{Z}_{10}^{0}$ medium [16] containing $\mathrm{NaCl}\left(10 \mathrm{~g} \mathrm{l}^{-1}\right)$ and lacking nitrogen and the purchased isolate was maintained in Z8 medium. They were grown in the laboratory at $25{ }^{\circ} \mathrm{C}$ an under light intensity of $20.8-27.4 \times 10^{-6} \mathrm{E} \mathrm{m}^{-2} \mathrm{~s}^{-1}$ with a light/dark cycle of $14 / 10$ h. Cultures were unicyanobacterial and non-axenic. After 4-8 weeks of growth, cyanobacteria cells were extracted from the culture medium by filtration, washed once with bidistilled water, frozen at $-20{ }^{\circ} \mathrm{C}$ and freeze-dried.

\subsection{Phenotypic characterization and identification}

For phenotypic analysis, the length and width of vegetative cells, heterocysts and, when present, akinetes of 4-week-old cultures were measured. Examination was carried out using a Leica Q500IW microscope with a digital camera, and LEICA QWIN standard V 2.3 image analysis software. Fifty cells were measured, but when akinetes were scarce, measurements were done on 25 cells. The presence or absence of gas vesicles was recorded. Morphological description was carried out according to the current classification system $[6,14]$.

\subsection{Statistical analyses}

The average and standard deviations of the sizes of cells were calculated for each Nodularia isolate using Statistica software system, version 7 [34]. One-way analysis of variance (ANOVA) using Statistica was employed to evaluate differences in length and width of vegetative cells and heterocysts between isolates. We used the Kolmogorov-Smironov as goodness-of-fit procedure. Since normal distribution was not assessed, logarithmic transformation was applied to the data. We consider the data significantly different if their $p$-values were less than or equal to 0.05 .

Principal components analysis (PCA) of the mean lengths and widths of vegetative cells and heterocysts of the two Nodularia isolates from Portugal plus cell dimensions of Nodularia strains described previously in Laamanen et al. [17] was performed using Statistica. 


\subsection{Acute toxicity assay}

Toxicity was screened using Artemia salina nauplii with $24 \mathrm{~h}$ hatching and performed in a 96-well microplate. Briefly, the biomass of the LEGE06071 isolate (100 mg dry wt) was extracted with an elutropic series of three solvents, hexane- $n$, methanol and water. Each extract was homogenized by sonication with an ultrasound probe Vibra cell 50 (Sonics \& Materials Inc. Danbury, CT, USA) for $3 \times 20 \mathrm{~s}$ on ice, and centrifuged at $9300 \times \mathrm{g}$ for $10 \mathrm{~min}$. The supernatant was collected and evaporated. The dried extract was suspended in $1 \mathrm{ml}$ of artificial sterilized seawater and filtered through a $0.22 \mu \mathrm{m}$ filter.

To each well containing $200 \mu \mathrm{l}$ of extract at different concentrations, 10-20 nauplii were added, as well as for controls. For the control trial, we used artificial filtered seawater and solvent evaporated and then resuspended in seawater. Three replicates were done for all concentrations. The microplate was covered and incubated at $25{ }^{\circ} \mathrm{C}$ in darkness. After $24 \mathrm{~h}$ and $48 \mathrm{~h}$, the number of dead nauplii in each well were counted. The larva was considered dead if no movement was recorded over $30 \mathrm{~s}$. As a positive control we used potassium dichromate (Sigma-Aldrich, USA).

The total number of nauplii per well was determined following Lugol's fixation. Results were presented as a graph of the mortality percentage versus the concentration. $\mathrm{LC}_{50}$ values and associated 95\% confidence intervals were estimated by the Probit method, the Spearman-Karber method and the Trimmed Spearman-Karber method depending on the number of partial mortalities.

\subsection{Genotoxicity activity analysis in vitro}

The screening of genotoxicity was performed with the SOS-Chromotest kit, version 6.3, (EBIP, Canada). The kit is based on a genetically engineered Escherichia coli with an enzyme gene, $\beta$-galactosidase, linked to its S.O.S operator gene. The biomass of the isolate ( $25 \mathrm{mg}$ dry wt) was extracted with 70:30 (v:v) methanol: water (Merck, Germany) to a final concentration of $25 \mathrm{mg} \mathrm{ml}^{-1}$. The extract was homogenized by sonication with an ultrasound Vibra cell 50 probe (Sonics \& Materials Inc., Danbury, CT, USA) for $3 \times 20 \mathrm{~s}$ on ice following $1 \mathrm{~h}$ incubation on ice and was centrifuged at $9300 \mathrm{~g}$ for $10 \mathrm{~min}$. The supernatant was then collected and evaporated. The dried extract was suspended in $1 \%$ DMSO and filtered through a $0.22 \mu \mathrm{m}$ filter. $\beta$-galactosidase ( $\beta$-gal) and alkaline phosphatase activities (PAL) were then measured at 615 and $405 \mathrm{~nm}$, respectively, using a PowerWave ${ }^{\mathrm{TM}}$ microplate spectrophotometer (BioTek, USA). The induction factor (IF) for a concentration $c$ of the sample was defined as $R_{\mathrm{c}} / R_{0}$, $\left(R_{\mathrm{c}}=\beta\right.$-gal/PAL) where $R_{0}$ was the ratio measured in the negative control (sterile ultrapure water). As a standard, $10 \mu \mathrm{g}$ $\mathrm{ml}^{-1}$ of 4-nitroquinoline oxide (4NQO) was used.

\subsection{Mutagenicity testing in vitro}

The mutagenic assay was performed with the Muta-ChromoPlate $^{\mathrm{TM}}$ bacterial strain kit version 3.1 (EBIP, Canada) based on the validated bacterial reverse-mutation test, known as the Ames test. The extraction method used in this analysis was similar to that used in the SOS test above, except that the dried extract was suspended in 10\% DMSO. Briefly, we used one mutant strain of Salmonella typhimurium, TA100, carrying mutations in the operon coding for histidine synthesis and lacking microsomal activation (S9). As a positive control, we used sodium azide $(0.5 \mu \mathrm{g} 100 \mu \mathrm{l})$. Three replicates were done and the mutagenicity ratio was calculated as the ratio of revertants of the sample and the revertants of the blank control.

\subsection{DNA extraction and amplification of the $16 \mathrm{~S}$ rRNA gene}

Genomic DNA was isolated with the Aquapure genomic DNA kit (Bio-Rad) following the manufacturer's instructions. The 16S rRNA gene sequence (approximately $1400 \mathrm{bp}$ ) was obtained using two specific set of primers, 27F/809R and 740F/1494R [10,24]. The PCR conditions included an initial denaturation step at $92{ }^{\circ} \mathrm{C}$ for 2 min followed by 30 cycles of $92{ }^{\circ} \mathrm{C}$ for $20 \mathrm{~s}, 50{ }^{\circ} \mathrm{C}$ for $30 \mathrm{~s}, 72{ }^{\circ} \mathrm{C}$ for 2 min and a final extension step at $72{ }^{\circ} \mathrm{C}$ for $7 \mathrm{~min}$.

PCR products were analyzed by $1 \%(\mathrm{w} / \mathrm{v})$ agarose gel electrophoresis in Tris-acetate-EDTA (TAE) buffer $1 \times$, stained with ethidium bromide and visualized with UV. PCR products were purified using NucleoSpin ${ }^{\circledR}$ Extract II (Macherey-Nagel, Germany) and sequenced. The sequences obtained have been deposited in the GenBank database under the accession number FJ830639 (LEGE06071) and FJ977627 (ACOI00729).

\subsection{MALDI-TOF MS analysis}

Freeze-dried material from the LEGE06071 isolate was screened for a wide range of molecules by matrix-assisted laser desorption/ionization time of flight spectrometry (MALDI-TOF MS) according to Welker et al. [37].

\subsection{ELISA analysis}

Nodularin production was analyzed using a highly sensitive enzyme-linked immunosorbent assay (ELISA), the Qualitube $^{\mathrm{TM}}$ tube kit (Envirologix ${ }^{\mathrm{TM}}$, USA), following the manufacturer's instructions. Fresh material was frozen and thawed, disrupted by sonication on ice for $1 \mathrm{~min}$ and centrifuged at $9300 \mathrm{~g}$ for $10 \mathrm{~min}$. Prior to analysis, the disrupted cells were filtered with $0.45 \mu \mathrm{m}$ pore filters.

\subsection{Cyanotoxin gene analysis}

Primer pair HEPF (5'-TTTGGGGTTAACTTTTTTGGCCATAGTC- $\left.3^{\prime}\right)$ /HEPR ( $5^{\prime}$-AATTCTTGAGGCTGTAAATCGG GTTT-3') was used to assess the presence of the nodularin gene following Jungblut and Neilan [10]. As a positive control, we used a nodularin producer species. We also used mcyACd1R (5'-AAAAGTGTTTTATTAGCGGCTCAT- $\left.{ }^{\prime}\right)$ and 
A

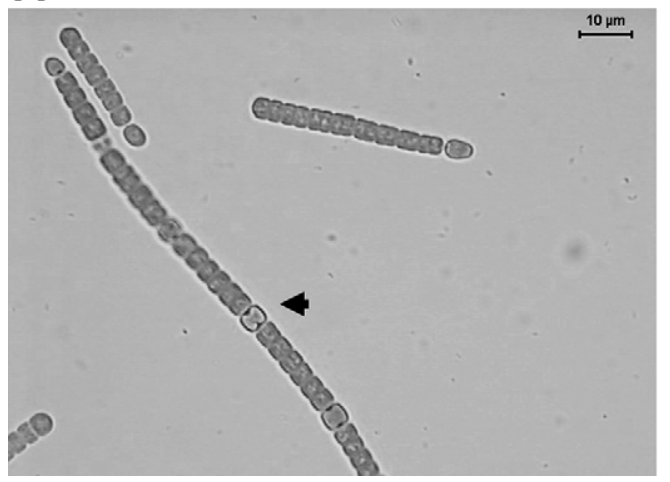

B

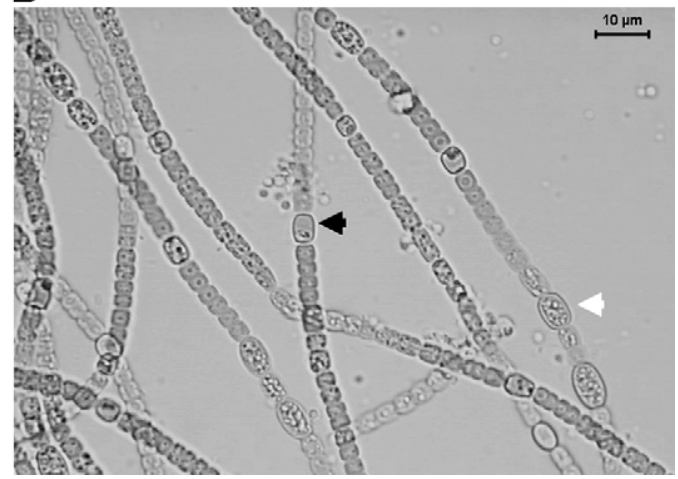

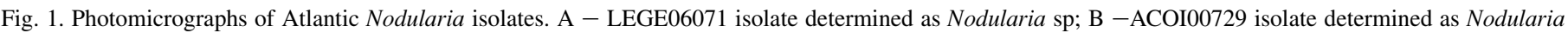
sphaerocarpa. Heterocytes are pointed out with black arrows and akinetes (when present) with white ones. Bar $-10 \mu \mathrm{m}$.

$m c y A-\mathrm{Cd} 1 \mathrm{~F}\left(5^{\prime}\right.$-AAAATTAAAAGCCGTATCAAA-3'), DKF $\left(5^{\prime}\right.$-GTGCCGGTNCC(A/G)TGNG(T/C)(T/C)TC- $\left.3^{\prime}\right)$ and DKR $\left(5^{\prime}\right.$-GCGATGGA(T/C)CCNCA(A/G)CA(A/G)(C/A)G-3') and MTF2 (5'-GCNGG(C/T)GG(C/T)GCNTA(C/T)GTNCC3 ${ }^{\prime}(\mathrm{AG}$ GAYVP, core motif I) and MTR (5'-CCNCG(AGT)AT(TC)TT NAC(T/C)TG-3'(QVKIRG, core motif V)) primers for PCR amplification of the condensation domain of the $m c y A$ region, the NRPS A-domain and the PKS KS-domain, respectively. PCR conditions used have been described by Hisbergues et al. and Barrios-Llerena et al. [2,9].

\subsection{Phylogenetic analyses}

$16 \mathrm{~S}$ rRNA gene sequences obtained were aligned with reference sequences retrieved from GenBank using the ClustalW program version 4.0 in MEGA4 [36]. Phylogenetic trees were constructed with Neighbor-joining (NJ), maximum parsimony (MP), maximum likelihood (ML) and Bayesian (BY) algorithms using Paup 4.0b10 [35] and MrBayes 3.1.2 [29]. NJ analysis was constructed with HKY 85 distances followed by a branch-swapping procedure. MP analysis was conducted using a heuristic search, with random additions of taxa and tree-bisection-reconnection branch-swapping. ML analysis was done after selecting the best evolutionary model fitting the data $(\mathrm{GTR}+\mathrm{I}+\mathrm{G})$ using MODELTEST 3.7 [26]. Tree topology reliability was assessed by 100 bootstraps. Bayesian analysis was obtained with Markov chain Monte Carlo (MCMC) sampling in MrBayes [29]. We used a GTR substitution model with the invariant site plus gamma options (five categories). One cold and four incrementally heated chains were run for 2,000,000 generations with chains $\mathrm{I}=2,3,4$ and 5 incrementally heated, with heat being $1 /(1+[i-1] \mathrm{T})$ and $T=0.2$. Trees were sampled every 100 generations from the last 1,000,000 generated (well after the chain reached stationary phase) and 10,000 trees were used for inferring Bayesian posterior probability.

For sequence alignment, we used the following 16S rRNA Nodularia sequences retrieved from GenBank: AJ781137, AJ781138, AJ781134, AY038034.1, EF087989.1, AJ781140,
AJ133182, AJ781141.1, AF268021.1, AJ781151.1, AJ781144.1, AJ133183, AJ781143.1, AJ781145.1, DQ185243. We used as outgroups FM242086 (Anabaena lemmermannii), FM242087 (Anabaena flos-aquae), AJ133152 (Anabaena sp.strain14), AM711546 (Nostoc sp.) and EU031807.1 (Trichormus sp.).

\section{Results}

\subsection{Phenotypic features of the isolates and nodularin gene analysis}

As described by Komarék et al. [14], LEGE06071 was identified within the Nodularia genus and with mixed features between $N$. sphaerocarpa and $N$. harveyana, whilst ACOI00729 was identified as $N$. sphaerocarpa. In both isolates, the trichomes were straight to slightly waved and the cells were barrel-shaped (Fig. 1A and B). In addition, the vegetative cells of ACOI00729 appeared with small granules (Fig. 1B). LEGE06071 heterocysts were barrel-shaped to almost spherical instead of having a rectangular form like the ACOI0729 heterocytes. Neither of the two isolates had aerotopes.

The length and width of vegetative cells varied from 3.10 to $3.15 \mu \mathrm{m}$ and from 3.71 to $4.25 \mu \mathrm{m}$, respectively (Table 1). Vegetative cells were wider rather than shorter (Table 1, Fig. 1A and B), with a length:width (1: w) ratio of vegetative cells varying from 0.72 (LEGE06071) to 0.84 (ACOI00729). Heterocysts were 3.91-4.89 $\mu \mathrm{m}$ long and 4.20-4.74 $\mu \mathrm{m}$ wide (Table 1). Using the same medium, we were able to observe akinetes only in ACOI00729, with length and width varying from 7.57 to $5.39 \mu \mathrm{m}$, respectively. An attempt was made to induce akinetes in LEGE06071 by removing nitrogen and adding salinity, but without success. Using BG11 medium [1] without nitrogen medium, akinetes were induced, with dimensions of $5.56 \pm 0.72 \mu \mathrm{m}$ width and $5.93 \pm 0.58 \mu \mathrm{m}$ length.

The mean length of vegetative cells and heterocysts did not differ significantly between the two species $(p=0.597$ and $p=0.094)$, while the mean width was significantly different $(p=0.000$ and $p=0.002)$. 
PCA dimensions of Portuguese isolates (Fig. 2), together with the mean cell dimensions of the three main species of Nodularia given in Laamanen et al. [17], placed the two isolates as a differentiated group, but located near the reference strains of $N$. baltica and $N$. harveyana, suggesting they have morphological dimensions nearest to $N$. harveyana species.

The nodularin synthetase gene could not be detected by PCR amplification, suggesting the absence of the gene and non-production of nodularin on both Nodularia isolates, which was further confirmed by ELISA analysis (data not shown).

\subsection{Phylogenetic analyses}

Phylogenetic analyses were carried out to confirm whether both isolates belonged to the Nodularia genus. 16S rRNA partial sequences of LEGE06071 (1415 bp) and ACOI00729 (758 bp) were compared with available $16 \mathrm{~S}$ sequences in GenBank from various species of Nodularia and outgroups representative of Anabaena, Nostoc and Trichormus genera. Bootstrap analyses were conducted to measure the reliability of the observed phylogenetic patterns and revealed well-supported topologies that were mostly congruent among the different tree-reconstruction methods used (Fig. 3). For all tree-reconstruction methods, a high bootstrap value $(>95 \%)$ was obtained, indicating that isolates studied belonged to the Nodularia genus. Moreover, they did not cluster with either $N$. spumigena or $N$. harveyana.

\subsection{Bioactivity screening against Artemia and bacteria}

LEGE06071 showed acute toxicity against Artemia nauplii. Since the negative control values were below $10 \%$, we

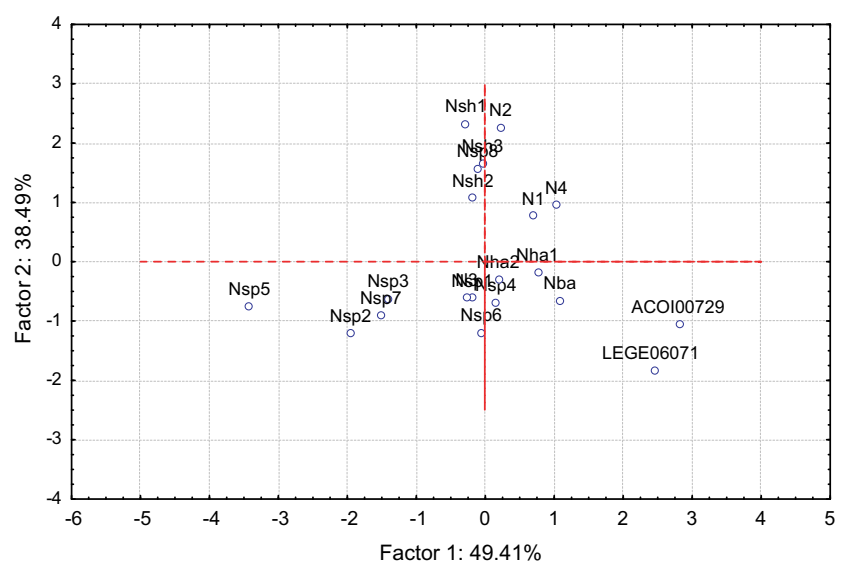

Fig. 2. Principal Component Analysis (PCA) of the average dimensions of the vegetative cells and heterocytes of the LEGE06071 and ACOI00729 isolates, and those of the species descriptions of Nodularia given in Laamanen et al. [14] Factor 1(length) and 2 (width) accounted for $87.90 \%$ of the variability in the data. Ns-N. spumigena Hübel 1988/306a; Ns2-N. spumigena Hübel 1988/ 306b; Ns3-N. spumigena Hübel1987/310; Ns4-N. spumigena Hübel 1987/311; Ns5-N. spumigena NSPI-05; Ns6-N. spumigena NSOR-12; Ns7-N. spumigena GR8b; Ns8-N. spumigena; $\mathrm{Nb}-N$. baltica BY1; N1-Nodularia sp. F81; N2-Nodularia sp. AV3; N3-Nodularia sp. AV63; N4- Nodularia sp. HEM; N5-Nodularia sp. PCC7804; Nsh1 - Nodularia sphaerocarpa UP16a; Nsh2Nodularia sphaerocarpa UP16f; Nsh3-Nodularia sphaerocarpa HKVV; Nsh4Nodularia sphaerocarpa PCC73104/1; Nha - Nodularia harveyana Hübel $1983 / 300$. 
considered the test valid. We observed that the aqueous extract at $24 \mathrm{~h}$ did not induce dose-dependent effects. The same was true for the methanol extract with the same exposure time. No induced effects were observed for hexane extract at $24 \mathrm{~h}$, since mortality percentage values were below the control. Only $48 \mathrm{~h}$ values for methanol and aqueous extracts followed a dosedependent effect. The LC50 value for the crude extract of methanol was estimated at $17.81 \mathrm{mg} \mathrm{ml}^{-1}$ with $95 \%$ confidence limits between 11.63 and 27.30 (30.43\% Trim), and for the aqueous extract the value was $53.21 \mathrm{mg} \mathrm{ml}^{-1}$ with $95 \%$ confidence limits from 37.97 to $65.94\left(\mathrm{X}^{20.05 \text { level }}=11.070\right)$. For the hexane crude extract, the mortality percentage was below 50\%. Average mortality (in percentage) data of the three extracts analyzed are shown in Fig. 4. The crude methanol and aqueous extract showed the highest mortality values. The estimated 24 and $48 \mathrm{~h}-\mathrm{LC}_{50}$ values and $95 \%$ confidence limits of the positive control, potassium dichromate, were 69.91 (56.08-84.12) and $16.62 \mathrm{mg} \mathrm{ml}^{-1}$ (7.95-24.91), respectively. No mortality for methanol or water controls was observed (Fig. 5).

In genotoxic analysis, no activity was found on the $70 \%$ methanol LEGE06071 extract, as expressed by IF values below 1.0 (data not shown). We considered this to be genotoxic if the IF parameter was higher than 1.5, although the value differed between authors, [21,30].

Regarding the mutagenicity of LEGE06071, the number of spontaneous revertants obtained was 8 , while revertants induced by 2-nitrofluorene ( $10 \mu \mathrm{g}$ per microplate, positive control) numbered 96. Experiments showed no mutagenicity for the different tested doses of LEGE06071, since 9 revertants were obtained (data not shown).

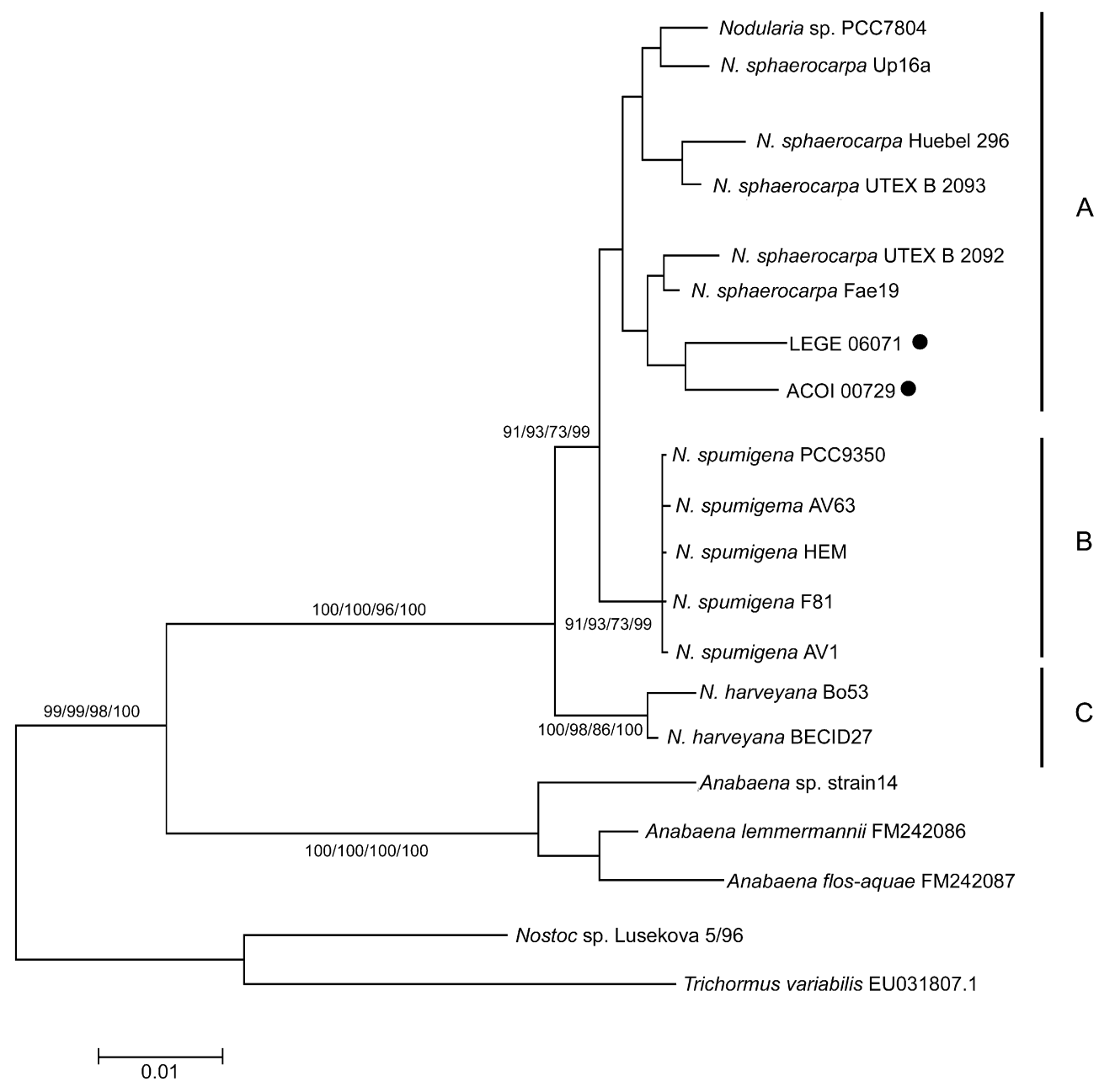

Fig. 3. Phylogenetic relationships of the LEGE06071 and ACOI0729 Nodularia strains from Atlantic environments (highlighted with black dots). The represented phylogenetic tree was constructed using the neighbor-joining algorithm (see material and methods). Bootstrap values are placed at major branch points for the neighbor-joining (NJ), maximum parsimony (MP), maximum likelihood (ML) and Bayesian (BY) phylogenetic analyses, respectively (NJ/MP/ML/BY). The Bayesian posterior probability is shown as percentages (i.e. 95 represents a posterior probability of 0.95). The Nodularia clades are indicated with the letters A, B and C corresponding to N. sphaerocarpa, N. spumigena and N. harveyana, respectively. Sequences retrieved from GenBank: AJ781137 (N. spumigena F81), AJ781138 (N. spumigena AV63), AJ781134 (N. spumigena HEM), AY038034.1 (N. spumigena PCC9350), EF087989.1 (N. spumigena AV1), AJ781140 (N. sphaerocarpa UP16a), AJ133182 (N. sphaerocarpa UP16f), AJ781141.1(N. sphaerocarpa 296), AF268021.1 (N. sphaerocarpa UTEX B 2093), AJ781151.1 (N. sphaerocarpa UTEX B 2092), AJ781144.1 (N. sphaerocarpa Fae19), AJ133183 (N. sphaerocarpa HKVV), AJ781143.1 (N. harveyana Bo53), AJ781145.1 (N. harveyana BECID27), DQ185243 (Nodularia sp. PCC7804). We used as outgroups: FM242086 (Anabaena lemmermannii), FM242087 (Anabaena flos-aquae), AJ133152 (Anabaena sp.strain14), AM711546 (Nostoc sp.) and EU031807.1 (Trichormus sp.). 


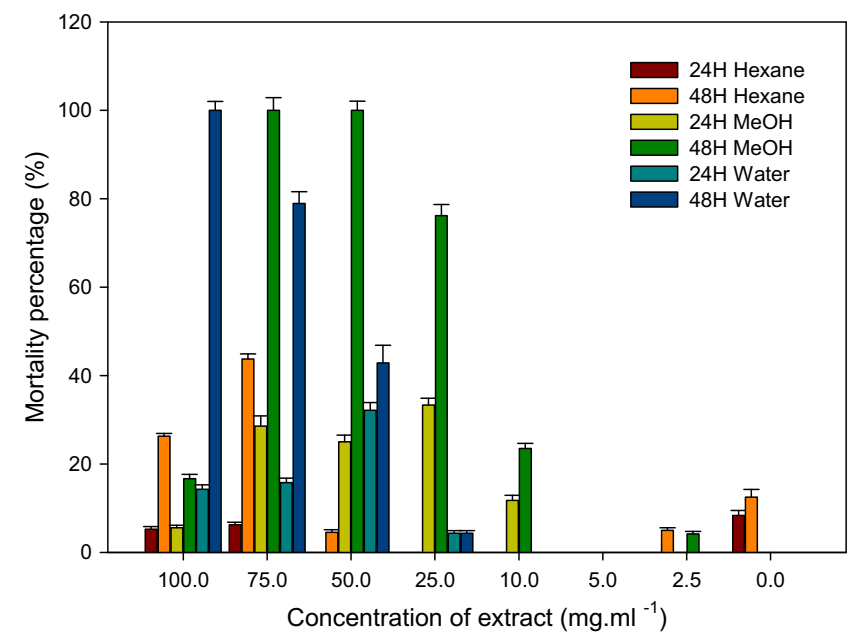

Fig. 4. Mean values of mortality percentage $(\% \pm$ SE) of instar II Artemia nauplii exposed to hexane, methanol and aqueous extracts of LEGE06071 isolate during 24 and $48 \mathrm{~h}$.

Crude extract of LEGE06071 was also analyzed by MALDI-TOF MS, and we confirmed the non-presence of nodularin and other known cyanotoxins. Although our isolate is a non-nodularin producer, we observed other compounds by MALDI-TOF analysis (Fig. 5). The most intense peaks fit in glycolipids and other unknown compounds (not peptidic) at $m / z$ 726.98, 742.96, and 773.55, 789.50 Da respectively.

\section{Discussion}

To our knowledge, no previous study has reported the occurrence of Nodularia species in Atlantic environments and, in particular, in Portuguese estuary salt pans. In this study, we report for the first time the presence of the genus Nodularia in
Atlantic estuarine environments characterized at the phenotypic, toxicological and molecular level. LEGE06071 and ACOI00729 isolates were identified as species of the Nodularia genus according to classical taxonomy [13-15]. LEGE06071 shared characteristics with both $N$. sphaerocarpa and $N$. harveyana, which fit more closely with the description of $N$. sphaerocarpa, while ACOI00729 was identified as $N$. sphaerocarpa. We observed the absence of aerotopes on both isolates, a characteristic shared by most typical benthic strains of $N$. sphaerocarpa and $N$. harveyana species. The benthic origin was confirmed only for the LEGE06071 isolate, while for ACOI00729, it is known only that it came from a flowing environment. Morphometric data obtained were congruent with classical classification and suggest that the isolates fall within the benthic $N$. sphaerocarpa and $N$. harveyana descriptions. However, identification based on morphological features did not provide a clear-cut identification of the isolates at the species level. PCA analysis placed the isolates nearest to the $N$. harveyana and $N$. baltica species, but as a differentiated group.

In addition, 16S rRNA gene sequence analyses confirmed, with high bootstrap support ( $>95 \%$ ) for all tree-reconstruction methods used, that the isolates belong to the Nodularia genus. Although the isolates did not cluster with either $N$. spumigena or $N$. harveyana, they showed a close relationship with $N$. sphaerocarpa. Molecular analysis of the nodularin synthetase gene cluster indicated that none of the isolates was a potential nodularin producer. This result is in accordance with previous reports [22,31] since, to date, only one $N$. sphaerocarpa strain showed the presence of the nodularin gene. The data suggest that the LEGE06071 isolate does not pose a potential hepatotoxic risk, similarly to other benthic Nodularia species. Nevertheless, this genus is known to produce other secondary metabolites which can be toxic to

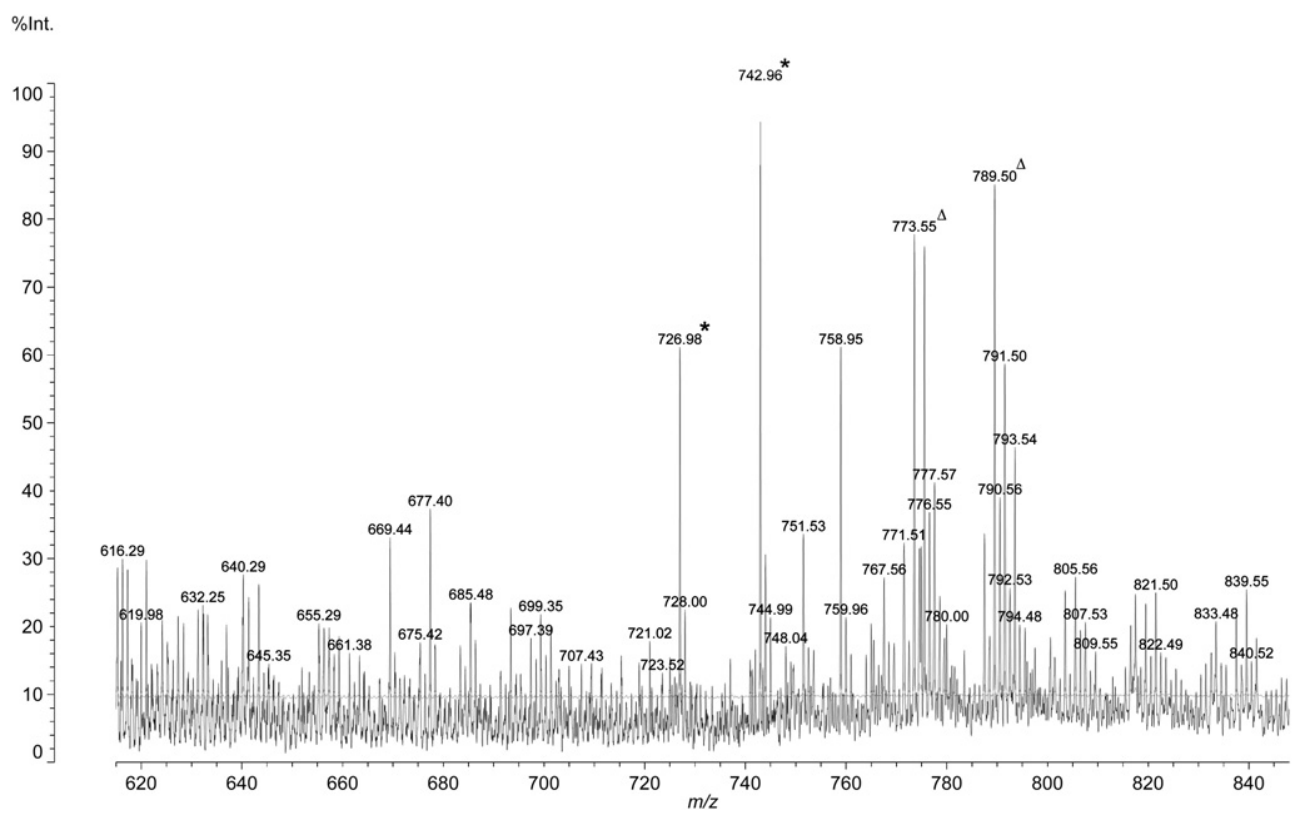

Fig. 5. MALDI-TOF spectrum of LEGE06071 extract, scanning ion mass from 600 to $800 \mathrm{~m} / \mathrm{z}$. Chlorophyll-a derivatives, pheophorbide-a and pheophytin-a ( $\mathrm{m} / \mathrm{z}$ 593.28 and $871.57 \mathrm{Da}$, respectively), were used as internal standards. Asterisks are indicative of non-peptidic compounds and delta symbols represent (glyco)lipids. 
humans, animals and plants [19,38]. Indeed, MALDI-TOF analysis revealed several intense peaks of glycolipids and other unknown substances that need to be further evaluated. To examine the possibility of toxicity caused by other putative metabolites we performed toxicological assessment against three different organisms important in the food chain, specifically, in two bacteria, E. coli and S. typhimurium and in the crustacean, Artemia salina.

In vitro genotoxicity and mutagenicity testing retrieved negative results, suggesting that LEGE06071 does not produce potential genotoxic or mutagenic compounds. In particular, the absence of mutagenicity for LEGE06071 indicated that it did not cause the base-pair substitution mutation on GC pairs in the genetically modified histidine operon. Nevertheless, given the fact that other reversion events may occur on Salmonella tester strains (frameshifts, transitions and transversion mutations not yet studied), we cannot rule out that LEGE06071 could still pose mutagenic risk to human health. Moreover, the non-presence of metabolic activation systems could lead to a putative negative mutagenic response. In fact, some important classes of substances, such as aromatic amines and polycyclic aromatic hydrocarbons, show low mutagenic activity unless they are metabolized to active forms. Contrasting with humans and animals, bacteria do not have the metabolic capacity to convert chemicals to DNA-reactive electrophilic forms [23]. Further studies with the incorporation of an S9 rat liver metabolic activation system on the mutagenic assay should be carried out.

In contrast, the Artemia assay appears to indicate that LEGE06071 is potentially ecotoxic to the instar II nauplii. The results indicate that toxicity is more prominent for crude methanolic and aqueous extracts after $48 \mathrm{~h}$ exposure. The mortality percentage followed a dose-response pattern and it was possible to determine $48 \mathrm{~h} \mathrm{LC}$ values of $17.81 \mathrm{mg} \mathrm{ml}^{-1}$ and $53.21 \mathrm{mg} \mathrm{ml}^{-1}$ for the methanol and aqueous crude extract, respectively. Curiously, for the methanol extract at 48 $\mathrm{h}$, a drop in the mortality percentage was observed from 75 to $100 \mathrm{mg} \mathrm{ml}{ }^{-1}$ of concentration. This may be explained by a variance of responses of individuals within a population, with some being susceptible and others resistant. We also speculate that this sudden drop might be due to the interaction of different substances in complex mixtures as extracts, acting with the same mode of action or even independently [8]. The fact that the crude methanolic and crude aqueous extracts were the most lethal against hexane ones suggests that toxicity inducer compounds belong to a polar fraction sustained by intense peaks of glycolipid groups observed in MALDI-TOF MS analysis.

Similar results with crude extracts were also found for two strains of the Nodularia genus against Artemia sp. by Kiviranta et al. [12]. Furthermore, Martins et al. [20], who performed acute toxicity analysis using Artemia nauplii, also reported toxicity for methanolic and crude marine cyanobacterial extracts. However, in contrast to previous reports [20], our results suggest that toxicity is much higher at $48 \mathrm{~h}$ exposure than at $24 \mathrm{~h}$ exposure. The present data indicate that the LEGE06071 is more toxic at a higher range of concentrations than those found for the marine cyanobacterial extracts of Martins et al. [20]. Moreover, our results are in agreement with studies by Sánches-Fortún et al. [32] and Caldwell et al. [4] who showed that Artemia sensitivity is achieved at or after 48 $\mathrm{h}$ of exposure.

In conclusion, the current work showed that LEGE06071 is a benthic Nodularia sp. specimen occurring in Atlantic environments, specifically in saltpan environment, sharing morphometric and phylogenetic characteristics with other benthic Nodularia from flowing water of the Madeira Island. In toxicological assessment, neither potential SOS induction on E. coli nor mutagenic activity was shown by LEGE06071. Nevertheless, the LEGE06071 isolate was identified as an inducer of ecotoxicity against Artemia nauplii, suggesting that the Nodularia isolate of estuarine systems can pose a potential risk to the aquatic ecosystem. The brine shrimp Artemia is one of the main pelagic invertebrates of marine and estuarine systems, functioning as grazer on phytoplankton as well as food for diverse invertebrates and fish larva [20]. The potential acute toxicity of Artemia may change the dynamics of the food chain in an estuarine environment. The correlation between a specific toxic compound and observed toxicity will require further study.

\section{Acknowledgements}

This work was supported by an SFRH/BD/32486/2006 grant from the Portuguese Governmental Foundation for Science and Technology (FCT). We also want thank Micaela Vale for the help in ELISA analysis.

\section{References}

[1] Allen, M.M., Stanier, R.Y. (1968) Growth and division of some unicellular blue-green algae. J. Gen. Microbiol. 51, 199-202.

[2] Barrios-Llerena, M.E., Burja, A.M., Wright, P.C. (2007) Genetic analysis of polyketide synthase and peptide synthetase genes in cyanobacteria as a mining tool for secondary metabolites. J. Ind. Microbiol. Biotechnol. 34, 443-456.

[3] Boyer, S.L., Flechtner, V.R., Johansen, J.R. (2001) Is the 16S-23S rRNA internal transcribed spacer region a good tool for use in molecular systematics and population genetics? A case study in cyanobacteria. Mol. Biol. Evol. 18, 1057-1069.

[4] Caldwell, G.S., Bentley, M.G., Olive, P.J.W. (2003) The use of the brine shrimp (Artemia salina) bioassay to assess the toxicity of diatom extracts and short chain aldehydes. Toxicon 42, 301-306.

[5] Carmichael, W.W. (1997) The cyanotoxins. Adv. Bot. Res. 27, 211-256.

[6] Castenholz, R.W. (2001) Phylum BX Cyanobacteria oxygenic photosynthetic bacteria. In G. Garrity, D.R. Boone, \& R.W. Castenholz (Eds.), Bergey's Manual of Systematic Bacteriology, (second ed.)The Archaea and the Deeply Branching and Phototropic Bacteria vol. 1 (pp. 473-599) New York: Springer-Verlag.

[7] Francis, G. (1878) Poisonous Autralian lake. Nature 18, 11-12.

[8] Groten, J.P., Feron, V.J., Sühnel, J. (2001) Toxicology of simple and complex mixtures. Trends Pharmacol. Sci. 22, 316-322.

[9] Hisbergues, M., Christiansen, G., Rouhiainen, L., Sivonen, K., Börner, T. (2003) PCR-based identification of microcystin-producing genotypes of different cyanobacterial genera. Arch. Microbiol. 180, 402-410.

[10] Jungblut, A.-D., Neilan, B.A. (2006) Molecular identification and evolution of the cyclic peptide hepatotoxins, microcystin and nodularin, 
synthetase genes in three orders of cyanobacteria. Arch. Microbiol. 185, 107-114.

[11] Kankaanpää, H., Sipiä, V., Kuparinen, J., Chizmar, J., Carmichael, W.W. (2001) Nodularin analyses and toxicity of Nodularia spumigena (Nostocales, Cyanobacteria) waterbloom in the western Gulf of Finland, Baltic Sea, in August 1999. Phycologia 40, 268-274.

[12] Kiviranta, J., Sivonen, K., Niemelà, S.I., Huovinen, K. (1991) Detection of toxicity of cyanobacteria by Artemia salina bioassay. Environ. Toxicol. Water Qual. 6, 423-436.

[13] Komárek, J., Anagnostidis, K. (2005) Cyanoprokaryota, Part 2, Oscillatoriales, Suüsswasserflora von Mitteleuropa. Heidelberg, Bd 19/2: Spektrum Akademischer Verlag. pp. 1-759.

[14] Komarék, J., Hübel, M., Hübel, H., Śmarda, J. (1993) The Nodularia studies 2 tax. Algol. Stud. 68, 1-25.

[15] Komarék, J., Kling, H., Komárková, J. (2003) Filamentous cyanobacteria. In J.D. Wehr, \& R.G. Sheath (Eds.), Freshwater Algae of North America (pp. 177-196). San Diego: Academic Press.

[16] Kotai, J. (1972) Instructions for Preparation of Modified Nutrient Solution Z8 for Algae. Oslo, Blindern: Norwegian Institute for Water Research. p. 5.

[17] Laamanen, M.J., Gugger, M.F., Lehtimäki, J.M., Haurakka, K., Sivonen, K. (2001) Diversity of toxic and nontoxic nodularia isolates (Cyanobacteria) and filaments from the Baltic Sea. Appl. Environ. Microbiol. 67, 4638-4647.

[18] Lehtimäki, J., Lyra, C., Suomalainen, S., Sundman, P., Rouhiainen, L., Paulin, L., Salkinoja-Salonen, M., Sivonen, K. (2000) Characterization of Nodularia strains, cyanobacteria from brackish waters, by genotypic and phenotypic methods. Int. J. Syst. Evol. Microbiol. 3, 1043-1053.

[19] Lyra, C., Laamanen, M., Lehtimäki, J.M., Surakka, A., Sivonen, K. (2005) Benthic cyanobacteria of the genus Nodularia are non-toxic, without gas vacuoles, able to glide and genetically more diverse than planktonic Nodularia. Int. J. Syst. Evol. Microbiol. 55, 555-568.

[20] Martins, R., Fernandez, N., Beiras, R., Vasconcelos, V. (2007) Toxicity assessment of crude and partially purified extracts of marine Synechocystis and Synechococcus cyanobacterial strains in marine invertebrates. Toxicon 50, 791-799.

[21] Mersch-Sundermann, V., Mochayedi, S., Kevekordes, S. (1992) Genotoxicity of polycyclic aromatic hydrocarbons in Escherichia coli PQ37. Mutat. Res. Genet. Toxicol. Environ. Mutagen. 278, 1-9.

[22] Moffitt, M.C., Neilan, B.A. (2001) On the presence of peptide synthetase and polyketide synthase genes in the cyanobacterial genus Nodularia. FEMS Microbiol. Lett. 196, 207-214.

[23] Mortelmans, K., Zeiger, E. (2000) The Ames Salmonella/microsome mutagenicity assay. Mutat. Res. 455, 29-60.

[24] Neilan, B.A., Jacobs, D., Del Dot, T., Blackall, L.L., Hawkins, P.R. Cox, P.T., Goodman, A.E. (1997) rRNA sequences and evolutionary relationships among toxic and nontoxic cyanobacteria of the genus Microcystis. Int. J. Syst. Bacteriol. 47, 693-697.

[25] Pearson, L.A., Moffitt, M.C., Ginn, H.P., Neilan, B.A. (2008) The molecular genetics and regulation of cyanobacterial peptide hepatotoxin biosynthesis. Crit. Rev. Toxicol. 38, 847-856.

[26] Posada, D., Crandall, K.A. (1998) MODELTEST: testing the model of DNA substitution. Bioinformatics 14, 817-818.

[27] Pushparaj, B., Pelosi, E., Caroppo, S. (2000) Effect of Nodularia harveyana biomass on the incidence of root-knot nematode (Meloidogyne incognita) in tomato. J. Appl. Phycol. 12, 489-492, 489-492.

[28] Pushparaj, B., Pelosi, E., Jüttner, F. (1999) Toxicological analysis of the marine cyanobacterium Nodularia harveyana. J. Appl. Phycol. 10, $527-530$.

[29] Ronquist, F., Huelsenbeck, J.P. (2003) MrBayes 3: Bayesian phylogenetic inference under mixed models. Bioinformatics 19, 1572-1574.

[30] Ruiz, M.J., Marzin, D. (1997) Genotoxicity of six pesticides by Salmonella mutagenicity test and SOS chromotest. Mutat. Res. Genet. Toxicol. Environ. Mutagen. 390, 245-255.

[31] Saito, K., Konno, A., Ishii, H., Saito, H., Nishida, F., Abe, T., Chen, C. (2001) Nodularin-Har: a new nodularin from Nodularia. J. Nat. Prod. 64, 139-141.

[32] Sánches-Fortún, S., Sanz, S., Barahona, M.V. (1996) Acute toxicity of several organophosphorous insecticides and protection by cholinergic antagonist and 2-PAM on Artemia salina larvae. Arch. Environ. Contam. Toxicol. 31, 391-398.

[33] Sivonen, K., Kononen, W., Carmichael, W.W., Dahlem, A.M., Rinehart, K.L., Kiviranta, J., Niemela, S.I. (1989) Occurrence of the hepatotoxic cyanobacterium Nodularia spumigena in the Baltic Sea and structure of the toxin. Appl. Environ. Microbiol. 55, 1990-1995.

[34] StatSoft, Inc. (2004) STATISTICA (Data Analysis Software System), Version 7.

[35] Swofford, D.L. (2001) PAUP4.0b10 Phylogenetic Analysis Using Parsimony and Other Methods' Computer Program. Sunderland, MA: Sinauer.

[36] Tamura, K., Dudley, J., Nei, M., Kumar, S. (2007) MEGA4: molecular evolutionary genetics analysis (MEGA) software version 4.0. Mol. Biol. Evol. 24, 1596-1599.

[37] Welker, M., Fastner, J., Erhard, M., Von Döhren, H. (2002) Application of MALDI-TOF MS in cyanotoxin research. Environ. Toxicol. 17, 367-374.

[38] Wiegand, C., Pflugmacher, S. (2005) Ecotoxicological effects of selected cyanobacterial secondary metabolites: a short review. Toxicol. Appl. Pharmacol. 203, 201-218.

[39] Wilmotte, A. (1994) Molecular evolution and taxonomy of the cyanobacteria. In D.A. Bryant (Ed.), The Molecular Biology of Cyanobacteria. Dordrecht: Kluwer. pp. 1-25. 